prevalence of HCV antibody was significantly greater in the prison population compared with the sexual health clinic population $(11.1 \% \mathrm{~V} 1.1 \%$, 2 sample test of proportion $\mathrm{p}<0.0005)$ however the prevalence in prisoners was unchanged from the 2007 estimate $(11.1 \% \mathrm{~V} 9 \%, 2$ sample test of proportion $\mathrm{p}<0.6)$. Injecting drug use was reported in $89 \%$ of HCV positive cases.

Conclusion The prevalence of $\mathrm{HCV}$ in our local institution remains high and injecting drug use is the most commonly reported risk factor. Implementing expanded testing strategies in prisons is a priority of great importance, along with further work to examine the effectiveness of currently strategies to address intravenous drug use.

1. Int J STD \& AIDS 2007 (18) 4: 228-30.

2. NICE PH43 http://guidance.nice.org.uk/PH43.

\section{P3.443 RISK BEHAVIOUR AND RISK FACTORS FOR HIV AND OTHER STI AMONG PRISONERS IN SERBIA}

doi:10.1136/sextrans-2013-051184.0893

M Krstic, I Ivanovic, M Vasic, M Zivkovic Sulovic. Institute of Public Health of Serbia, Belgrade, Serbia

Background The Strategy on HIV infection and AIDS 2011-2015, and the Strategic Plan for the Response to the HIV Epidemic in the Republic of Serbia, both recognise the need for conducting behavioural surveys every two years among populations most at risk to HIV.

Method The survey was conducted in 2012, as a third repeated cross-sectional (KAP) study on a representative sample of 613 respondents in 16 prisons in Serbia. The research instrument was a structured questionnaire completed by respondents.

Results The survey findings showed that syringe/needle sharing practises are much more present among those prisoners who have had experience of intravenous drug use (38.2\%), and who think drugs can be obtained inside a prison (32.8\%). Use of non-sterile tattooing tolls was reported by $13.1 \%$ prisoners. Sex with non-regular partners and irregular use of condoms is detected more often among male prisoners. Knowledge on HIV/AIDS is satisfactory among $31.6 \%$ prisoners, which is a lower percentage compared to 2010 (35.1\%). One in seven prisoners (15.2\%) in Serbia took HIV test during 12 months before the survey, and knows their result. Among prisoners included in the MoH of Serbia project "HIV Prevention/harm reduction among prisoners", a higher percentage of those with satisfactory level of knowledge on HIV/AIDS was detected (35.8\%), as well as those tested for HIV (32.9\%). Knowledge of prisoners related to sexually transmitted diseases is unsatisfactory, as prisoners do not recognise the symptoms, nor do they report to their physicians when they get them. The percentage of prisoners satisfied with healthcare services is significantly higher than in 2010 (38.3\% compared to $29.7 \%$ ).

Conclusion It is necessary to revise and redefine programme activities aimed at preventing HIV/AIDS in prisons, and pay specific attention to HIV prevention programmes among vulnerable groups: youth, women and injecting drug users in prisons.

\section{P3.444 MISSED STI AND HIV TESTING OPPORTUNITIES AMONG MALE PRISONERS IN ENGLAND}

doi:10.1136/sextrans-2013-051184.0894

${ }^{1} \mathrm{~K}$ Marsh, ${ }^{2} \mathbf{S}$ Chan, ${ }^{1} \mathrm{~N}$ Wheatley, ${ }^{1 S}$ Duffell, ${ }^{2 \mathrm{R}}$ Lau, ${ }^{1} \mathrm{G}$ Hughes. ${ }^{1}$ Health Protection Agency, London, UK; ${ }^{2}$ St Georges Hospital, London, UK

Background Prisoners are a vulnerable population potentially at higher risk of sexually transmitted infections (STI), including bloodborne viruses (BBV), yet are more likely to receive fragmented sexual health services (SHS). Until recently, information on STI
SHS provision and outcomes in this population has been limited in England.

Methods Following implementation of a new surveillance system, we assessed the quality of SHS received and outcomes among male prisoners seen by staff at 58 STI clinics during 2011 relative to other male attendees at all 209 clinics in England. Data on females were excluded due to small prisoner numbers. Significant differences were identified using chi-squared and t-tests. New STI diagnosis rates (DRs) were directly standardised using prisoners as the reference population.

Results Compared with other male STI clinic attendees ( $\mathrm{n}=627,976 ; 1,143,495$ visits), prisoners ( $\mathrm{n}=3,216 ; 4,490$ visits) were significantly younger ( 25 vs 28 years; $p<0.001)$, more likely to be of black ethnicity (13\% vs $11 \%)$, UK-born ( $90 \%$ vs $80 \%)$ and heterosexual (97\% vs $83 \%$ ). Standardized new DRs for prisoners versus male attendees were higher for genital warts $(5.5 \%$ vs $4.6 \%$; p-value $=0.003)$, hepatitis B $(0.4 \%$ vs $0.1 \%$; $p$-value $<0.001)$ and hepatitis C $(2.0 \%$ vs $0.0 \%$; p-value $<0.001)$ but lower for genital herpes $(0.3 \%$ vs $1.2 \%$; p-value $<0.001)$, chlamydia $(5.8 \%$ vs $9.3 \%$; p-value < 0.001$)$ and gonorrhoea ( $0.8 \%$ vs $1.6 \%$; p-value $=0.008)$. New acute hepatitis A, syphilis and HIV DRs were similarly low $(<0.5 \%)$ for both groups. Comprehensive sexual health screens (48\% vs $64 \%$; p-value $<0.001$ ) and HIV testing $(68 \%$ vs $80 \%$; p-value $<0.001)$ were offered less frequently to prisoners.

Conclusion We found high DRs of BBVs in prisoners, especially hepatitis C, but fewer diagnoses of bacterial STIs. As there were substantial missed STI testing opportunities in prisoners, however, bacterial STI DR estimates are likely understated. Efforts to improve opportunities for accessing STI and HIV testing services by prisoners should be a priority.

\section{P3.445 SCALING UP HIV PREVENTION SERVICES AMONG PRISONERS IN UGANDA - TASO JINJA EXPERIENCE}

doi:10.1136/sextrans-2013-051184.0895

M B Isabirye, E Musoke Seruma, S Nambafu, E Tayebwa, D Mpiima. The AIDS Support Organization(TASO) Uganda Limited, Jinja, Uganda

Background HIV prevalence in Uganda among inmates is $11.2 \%$, making it almost twice as high as the national prevalence rate estimated at $7.3 \%$. The Uganda prisons Services accommodates over 2,000 inmates living with HIV/AIDS with in its 224 units. Finding prisons with a holistic HIV/AIDS package are uncommon. Lack of accreditation of the clinic at the prison to provide HIV services, security threats to the public and service providers, overwhelming prevalence and inability of other service providers to have a package for inmates was the spring board for TASO Jinja in partnership with Kirinya Prisons to start the outreach.

Program description TASO services in Kirinya came as a result of a needs assessment and signing of a memorandum of understanding with the office of the Jinja District Health Office and Kirinya Prison services management. The out reach was inaugurated in 2009. Since then TASO Jinja has cared for 408 cumulative number of inmates where 42 females and 365 males of which $2.5 \%$ and $46 \%$ of males and females respectively are on ART.

TASO Jinja provides; a holistic HIV/AIDS care package. Lessons learned Offering healthcare to prisons is an entry point for HCT to the vulnerable groups thus the inmates. More prisons in Uganda are in need of urgent intervention for scaling up HIV/AIDS prevention in prisons.

No HIV services in most Ugandan prisons Few trained service providers to cater for the HIV/AIDS needs of inmates in prison Transfer of the inmates to and from other units without supportive documentation makes monitoring of the progress difficult. 
Recommendations The government to upgrade and accredit prison health units to offer comprehensive HIV/AIDS services Policies that enforce the rights of inmates to health services should be rejuvenated. Increase funding to improve service delivery.

Conclusion HIV/AIDS prevention can be scaled up among the inmates.

\section{P3.446 EXCELLENT EFFICACY OF PRITELIVIR (AIC316) IN SUPPRESSION OF GENITAL HERPES, A NOVEL DRUG AGAINST HERPES SIMPLEX VIRUS (HSV) TYPE 1 AND 2}

doi:10.1136/sextrans-2013-051184.0896

'A Birkmann, 'D McCormick, 'D Kropeit, 'B Timmler, 'S Stoelben, ${ }^{2} \mathrm{~A}$ Wald, ${ }^{3} \mathrm{H}$ Field, 'M P Richard, 'H Zimmermann, 'H Rübsamen-Schaeff. 'AiCuris GmbH \& Co. KG, Wuppertal, Germany; ${ }^{2}$ University of Washington, Seattle, WA, United States; ${ }^{3}$ University of Cambridge, Cambridge, UK

Genital Herpes is generally being caused by HSV-2, although genital infections with the "labial" herpes virus, HSV-1, have been increasing. Transmission of the herpes virus has become a major health concern since it also promotes transmission of other sexually transmitted diseases, e.g. HIV. Nucleoside analogues are widely used for treatment of genital herpes, but recurrences still occur after cessation of therapy and even under long-term treatment. Furthermore, genital transmission of HSV-2 cannot efficiently be prevented by existing drugs.

PRITELIVIR (AIC316) belongs to a novel class of antiviral compounds with activity against HSV-1 and HSV-2. In contrast to nucleoside analogues targeting the viral DNA polymerase PRITELIVIR (AIC316) prevents the de novo synthesis of viral DNA through inhibition of the viral helicase-primase complex. PRITELIVIR (AIC316) therefore does not require activation by the viral thymidine kinase and is protective for uninfected cells.

In vitro and in vivo, PRITELIVIR (AIC316) exhibited potent and rapid antiviral activity as well as superior efficacy against both HSV-1 and -2 compared to nucleoside analogues. In single and multiple dose phase I trials PRITELIVIR (AIC316) was safe with favourable pharmacokinetics resulting in a long half-life, indicative of efficacy with once per day dosing. In a recently completed phase II proof-of-concept and dose finding trial in subjects with genital herpes PRITELIVIR (AIC316) met the primary and secondary endpoint of the trial demonstrating excellent activity in reducing viral shedding in a dose dependent way and suppression of clinical symptoms, even with once weekly dosing. A head-to-head comparison trial with Valtrex is underway.

In conclusion, PRITELIVIR (AIC316) represents a highly active and novel treatment option for HSV-1 and -2 infections with very convenient dosing.

\section{P3.447 LEUKOCYTE EXTRACT MODULATES CELLULAR FACTORS INVOLVED IN HIV INFECTION}

doi:10.1136/sextrans-2013-051184.0897

'C B Fernandez-Ortega, 'D Casillas, ${ }^{2} \mathrm{M}$ Dubed, ${ }^{2} \mathrm{~L}$ Navea, ${ }^{1} \mathrm{~A}$ C Ramirez, 'L Lopez, 'T Paneque. 'Center for Genetic Engineering and Biotechnology, Havana, Cuba; ${ }^{2}$ AIDS Research Institute, San Jose, Cuba

Background Despite the therapeutic advances of antiretroviral, problems of drug resistance, latent viral reservoirs, and drug induced toxic effects that compromise effective viral control point to the need for new classes of anti-HIV drugs with different modes of action. An extract from human leukocyte called Dialyzable Leukocyte Extract (DLE) delays AIDS progression. However, the molecular bases supporting this effect are not completely comprehended. We hypothesises that active molecules from DLE modulate cellular factors involved in HIV infection.
Methods Using an in vitro infection model on MT4 cell line we demonstrated an inhibitory effect of DLE on HIV replication in treated cells which led us to identify molecules that could mediate this and other effects observed in this preparation.

Results DLE shows a significant inhibitory effect on HIV replication ranged from $80-90 \%$ according to the viral challenge. In addition, DLE shows modulation of important endogenous factors involved in HIV immunopathogenesis like TNFalpha and transcription factors NFkB and Sp1.

Conclusions DLE effect on cellular factors involved in HIV replication correlates with DLE inhibitory effect on HIV in vitro replication. The inhibition of HIV replication observed with DLE treatment could be mediated by TNF and transcriptions factors modulation involved in HIV infection. These finding could support the use of DLE on HIV patients and/or in health individuals to prevent the infection.

\section{P3.448 HPV AND ANOGENITAL WARTS. NEW ORIGINAL TREATMENT WITH ANALYSE AND OVERVIEW OF THE CURRENT CLINICAL SITUATION TODAY}

doi:10.1136/sextrans-2013-051184.0898

\section{E G Duray. Derma-Med Clinic, Budapest, Hungary}

Background HPV induced anogenital infections are the most common STI-s worldwide. According to WHO published data the incidence of them has dramatically raised in the past decade. Besides the high contagiosity benign epithelial lesions of the genitoanal region, the anogenital warts - HPV-s are responsible for development of most of the cervical neoplasias and other malignancies of the epithelial areas. Prevalence of HPV induced genital warts in the general population is $10 \%$ and affects $30 \%$ of sexually active young women at least $1 \mathrm{x}$ in their life. $65 \%$ of sexual partners of patients having condylomas will develop identical lesions in 9 months time. For the last decade no innovation has been proposed for treatment of anogenital warts. Currently available methods are based on surgical, chemical or immunological approaches.

Methods We have examined the efficacy and tolerability of an innovative cytotoxic method in the treatment of genitoanal condylomas in an international open prospective study. The cytodestructive effect is based on an innovative acid redox system (NO2-).

Results We have histological, clinical and virological evidence of the action of this system. The product is applied topically, it acts only locally, it doesn't destroy the basal membrane and induces mummification of the condyloma tissue. We have demonstrated by histological examination the similar activity of this procedure versus cryotherapy with the advantage of easier application, it is painless and doesn't need local anaesthesia.

Conclusion The treatment has great advantage in recurrent cases of genital warts by avoiding the need of repeated surgical procedures. It is also applicable for pregnant women, it doesn't need specific technical facilities and experience. This method has direct effect on HPV DNA.

\section{P3.449* THE PROMISE OF ESTRIOL CREAM FOR PREVENTION OF VAGINAL INFECTION IN PREMENOPAUSAL WOMEN}

doi:10.1136/sextrans-2013-051184.0899

${ }^{1}$ I. G. Dzuba, ${ }^{2}$ H. Jones, ${ }^{3} \mathrm{~S}$. A. Ballagh, ${ }^{4}$ W. H. Clark, ${ }^{5}$ S. Hillier, ${ }^{6}$ T. Irwin, ${ }^{7 P}$. Marx, ${ }^{8} \mathrm{~S}$ Smith, ${ }^{9}$ R. S. Veazey, 'B. Winikoff. 'Gynuity Health Projects, New York, NY, United States, ${ }^{2}$ CUNY School of Public Health at Hunter College, New York, NY, United States, ${ }^{3}$ Los Angeles County Harbor-UCLA Medical Center, Torrance, CA, United States, ${ }^{4}$ New York Presbyterian Hospital, New York, NY, United States, ${ }^{5}$ Magee-Womens Research Institute, Pittsburgh, PA, United States, ${ }^{6}$ University of Illinois at Chicago, Chicago, IL, United States, TTulane University School of Public Health and Tropical Medicine, New Orleans, LA United States, ${ }^{8}$ Smith Center for Infectious Diseases and Urban Health, East Orange, NJ, United States, ${ }^{9}$ Tulane National Primate Research Center, Covington, LA, United States. 